\title{
Videothoracoscopic repair of pectus excavatum with sternal transection for adult patients with nonelastic deformity
}

\author{
David Pérez, MD, PhD, Jose R. Cano, MD, Santiago Quevedo, MD, PhD, and Luis López, MD, PhD, \\ Las Palmas de Gran Canaria, Spain
}

\begin{abstract}
Minimally invasive repair techniques for pectus excavatum (PE) are thought to be contraindicated in patients with a rigid chest wall and to result in incomplete correction and more severe and prolonged postoperative pain for adult or late adolescent patients with a relatively malleable thorax. ${ }^{1}$ In these cases, additional procedures, such as osteotomy or insertion of a second bar, are required to achieve adequate correction. ${ }^{2}$ A new minimally invasive repair technique for PE successfully applied to patients with symmetric and rigid deformity is presented. This technique is a modification of the Nuss procedure, based on bilateral videothoracoscopic guidance and sternal transection, where the corrective bar has been modified in size and shape. Inasmuch as the involved bar is shorter and less bent than that in the original Nuss procedure, it can be inserted through minimal periareolar or submammary skin incisions with optimal cosmetic results. Sternal transection facilitates the elevation of the sternum, which results in highly satisfactory correction of the deformity and reduces the tension and pressure of the bar against the rib cage, thus potentially reducing postoperative pain.
\end{abstract}

\section{SURGICAL TECHNIQUE}

With the patient in the supine position, the distance between the external edges of both areolas is measured and a steel bar is selected that is only $2 \mathrm{~cm}$ longer than that distance. The bar is then bent with a mild curvature only at the ends. Two-centimeter bilateral periareolar (male patients) or submammary (female patients) incisions are made for inserting both the flexible thoracoscopic port (Flexipath; Ethicon Endo-Surgery, Blue Ash, Ohio) and the metal prosthesis. A 1-cm transverse incision is made on the sternal midline $2.5 \mathrm{~cm}$ above the trajectory planned for the intrathoracic bar, and the subcutaneous and muscular planes are dissected until the outer table of the sternum is reached.

From the Thoracic Surgery Section, Hospital Universitario Insular de Gran Canaria, Las Palmas de Gran Canaria, Spain.

Disclosures: Authors have nothing to disclose with regard to commercial support.

Received for publication Dec 9, 2010; revisions received Feb 1, 2011; accepted for publication Feb 18, 2011; available ahead of print April 1, 2011

Address for reprints: David Perez, MD, PhD, Thoracic Surgery Section, Hospital Universitario Insular de Gran Canaria, Las Palmas de Gran Canaria, Avda, Marítima del Sur s/n, CP: 35016 Spain (E-mail: cirujanoperez@hotmail.com).

J Thorac Cardiovasc Surg 2011;142:942-3

$0022-5223 / \$ 36.00$

Copyright (C) 2011 by The American Association for Thoracic Surgery doi:10.1016/j.jtcvs.2011.02.030

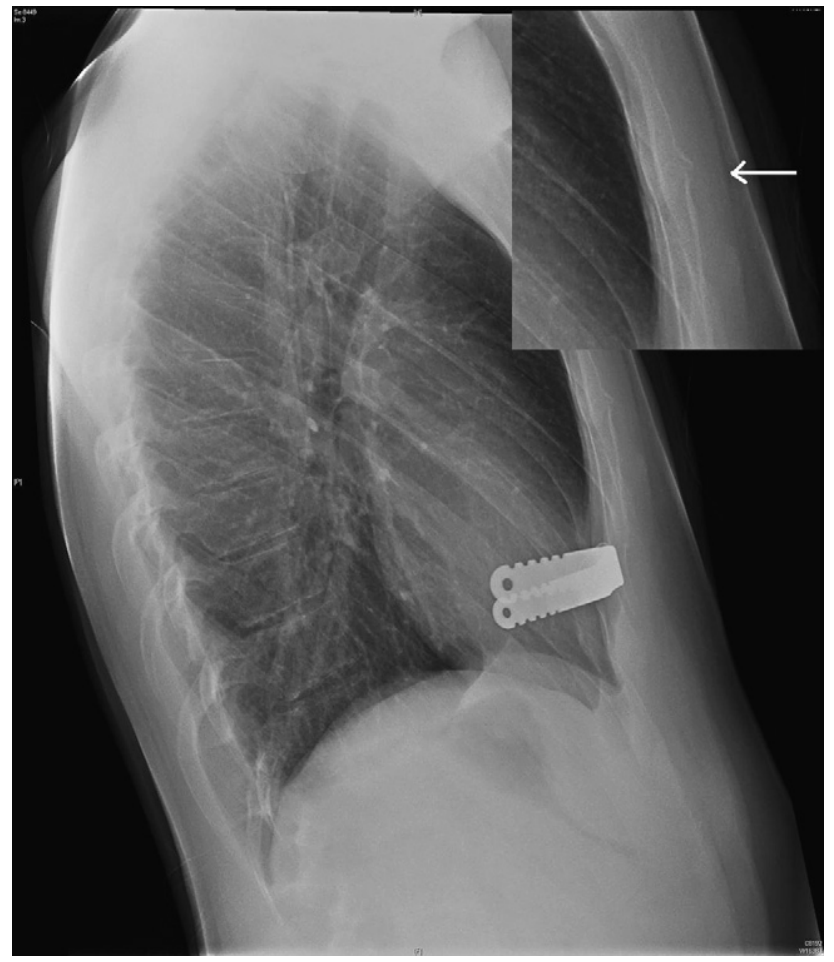

FIGURE 1. Radiography of the thorax showing the short bar and the transverse sternotomy (arrow).

A Lebsche knife (Codman and Shurtleff, Inc, Bridgewater, Mass) is then inserted with the cutting edge to the left-thus displacing the mammary vessels with the blunt edge-and the sternal body is gradually transected with the help of a hammer. This phase of the operation is terminated when bone resistance is perceived to decrease; at that point, the sternum is almost completely sectioned and the left mammary vessels are being approached. The maneuvers for inserting the bar are performed as described by Nuss, under endoscopic vision. Once the bar is completely introduced, the chest adopts a correct and stable shape (Figure 1). Both ends of the bar are then fixed into position by fastening them to the costal arch with metal wires to prevent lateral displacement. No chest drains are required. Postoperative scars heal quickly and are barely visible some weeks after the operation.

\section{DISCUSSION}

Because of its excellent cosmetic results and low associated comorbidity, the minimally invasive Nuss procedure is 


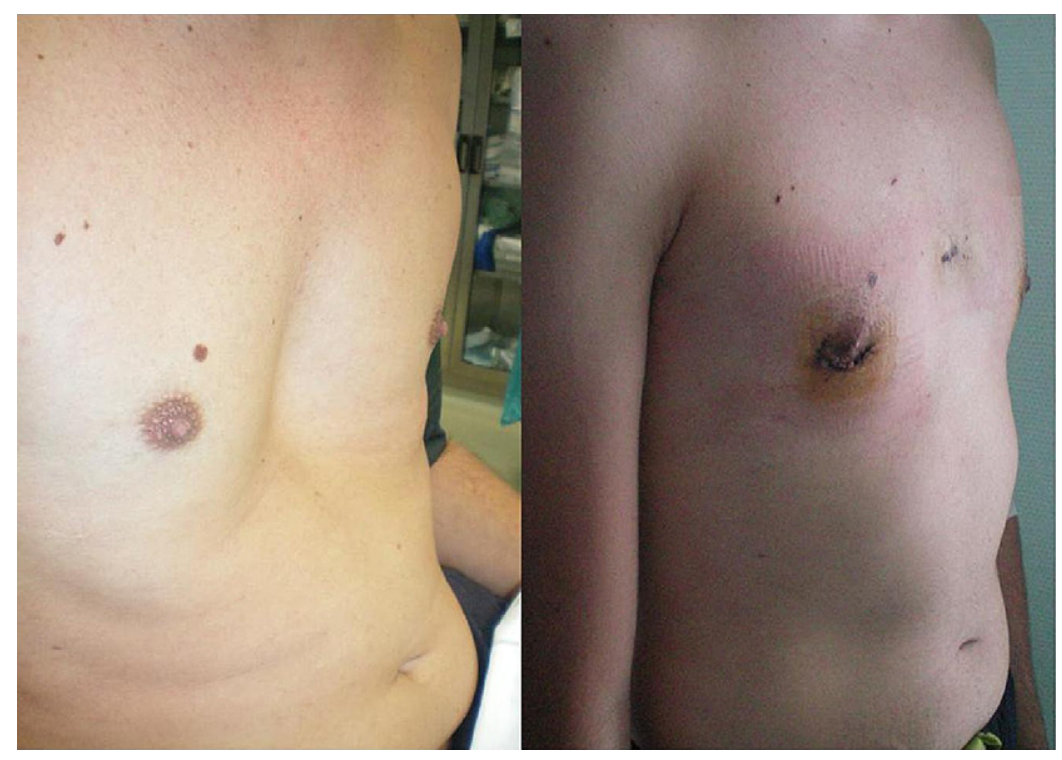

FIGURE 2. Preoperative and postoperative images.

the most suitable PE repair technique for most children and young adults. However, a recently published meta-analysis showed that PE correction techniques based on the Nuss procedure are associated with higher reintervention rates than open surgery, owing to deficient initial correction or to migration of the bar. ${ }^{3}$ Both factors are associated with poor thoracic elasticity, which results in the emergence of strong stress forces in the thorax after insertion of the bar. ${ }^{4}$ Sternal transection enhances elevation of the depressed sternum-thus improving immediate outcome-and reduces thoracic stress forces-thus preventing excessive pushing on the bar and unwanted secondary displacements. Furthermore, reducing thoracic stress is expected to reduce postoperative pain and to allow earlier removal of the bar inasmuch as it might become unnecessary after the sternal fracture heals in a correct position. The involved periareolar or submammary skin incisions are suitable for inserting corrective bars, provided that these have an adequate length and curvature, and offer optimal cosmetic results (Figure 2), as reported in a previous study. ${ }^{5}$ Asymmetric deformities require longer bars, which have an effect not only on the anterior thoracic wall but also on the lateral walls. In such cases, the standard Nuss procedure is recommended for patients with a still malleable thorax and the Ravicht procedure for patients with considerable thoracic stiffness.

\section{CONCLUSIONS}

The reported modified Nuss operation for symmetric PE is feasible and safe in adult patients. Sternal transection facilitates correction of the deformity and reduces the probability of bar migration. The involved shorter and mildly curved bar can be inserted through minimal periareolar or submammary incisions that leave barely visible scars. Such technical modifications do not increase the complexity of the classic Nuss procedure whereas they noticeably improve the cosmetic outcome and lead to high levels of patient satisfaction.

\section{References}

1. Kim do H, Hwang JJ, Lee MK, Lee DY, Paik HC. Analysis of the Nuss procedure for pectus excavatum in different age groups. Ann Thorac Surg. 2005;80: 1073-7.

2. Dzielicki J, Korlacki W, Janicka I, Dzielicka E. Difficulties and limitations in minimally invasive repair of pectus excavatum -6 years experiences with Nuss technique. Eur J Cardiothorac Surg. 2006;30:801-4.

3. Nasr A, Fecteau A, Wales PW. Comparison of the Nuss and the Ravitch procedure for pectus excavatum repair: a meta-analysis. J Pediatr Surg. 2010;45: 880-6.

4. Nagasao T, Miyamoto J, Tamaki T, Ichihara K, Jiang H, Taguchi T, et al. Stress distribution on the thorax after the Nuss procedure for pectus excavatum results in different patterns between adult and child patients. J Thorac Cardiovasc Surg. 2007;134:1502-7.

5. Pérez D, Cano JR, Quevedo S, López L. New minimally invasive technique for correction of pectus carinatum. Eur J Cardiothorac Surg. 2011;39:271-3. 